\title{
THEO DõI TÁC DỤNG KHÔNG MONG MUỐN CỦA BÀI THUỐc "TK1-HV” KẾT HỢP CẢNH TAM CHÂM ĐIỀU TRI HộI CHỨNG CỔ-VAI-CÁNH TAY DO THOÁI HÓA CộT SỐNG
}

\section{TÓM TẮT}

Mục tiêu: Theo dõi tác dụng không mong muốn của bài thuốc "TK1-HV" kết hợp cảnh tam châm trong quá trình điều trị hội chứng cổ-vai-cánh tay do thoái hóa cột sống. Đối tượng nghiên cứu: Bệnh nhân trên 18 tuổi được xác định mắc hội chứng cổ-vai-cánh tay. Phương pháp nghiên cứu: Nghiên cứu được tiến hành theo phương pháp can thiệp lâm sàng, so sánh trước và sau điều trị, có nhóm chứng. Bài thuốc TK1-HV sử dụng trong nghiên cứu thành phần gồm các vi thuốc có tên khoa học tuân thủ nguồn gốc dược liệu theo thông tư 05 năm 2015 của Bộ Y tế, Các vị thuốc được bào chế theo tiêu chuẩn Dược điển Việt Nam. Kết quả nghiên cứu: Không ghi nhận các tác dụng không mong muốn trên lâm sàng, dấu hiệu sinh tồn; không thấy sự thay đổi chỉ số huyết học và sinh hóa cơ bản sau 28 ngày sử dụng.

Tư khóa: Y học cô truyền, Hội chứng cổ-vai-cánh tay, TK1-HV; Tác dụng không mong muốn.

\section{SUMMARY}

\section{MONITORING THE UNDESIRABLE EFFECTS} OF THE DRUG "TK1-HV" IN COMBINATION WITH THE SCENE IN THE TREATMENT OF

\section{NECK-SHOULDER-ARM SYNDROME}

CAUSED BY DEGENERATIVE SPINE

Objectives: Monitoring the undesirable effects of the drug "TK1-HV" in combination with the scene in the treatment of neck-shoulder-arm syndrome caused by degenerative spine. Subject: Patients over 18 years old were identified with neck-shoulder-arm syndrome Methods: The study was conducted according to the clinical intervention method, comparing before and after treatment, with control group. TK1-HV remedies used in the study of ingredients include medicinal herbs with scientific names complying with medicinal origin according to Circular 052015 of the Ministry of Health, Medicines are prepared according to the standards of Vietnamese Pharmacopoeia. Results: No clinical undesirable effects, survival signs were noted; No change in baseline hematological and biochemical index was observed after 28 days of use.

Keywords: Traditional medicine; Neck-shoulderarm syndrome; TK1-HV; Unwanted effects

${ }^{1}$ Bệnh viện Y học cổ truyền Bộ công an Chịu trách nhiệm chính: Phạm Bá Tuyến Email: Tuyenmai66@yahoo.com.vn Ngày nhận bài: 24.11.2020

Ngày phản biện khoa học: 30.12.2020

Ngày duyệt bài: 8.01.2021
Phạm Bá Tuyến ${ }^{1}$, Đỗ Văn Đình ${ }^{1}$

\section{I. ĐĂT VẤN ĐỀ}

Hội chứng cổ-vai-cánh tay là một nhóm các triệu chứng lâm sàng liên quan đến các bệnh lý côt sống cổ có kèm theo các rối loạn chức năng rể, dây thần kinh cột sống cổ và/hoặc tủy cổ, không liên quan tới bệnh lý viêm [1], [2].

Nghiên cứu dịch tễ học được biết đến nhiều nhất là điều tra từ năm 1976 đến năm 1990 tại Rochester, Minnesota cho thấy tỷ lệ mắc hàng năm là 107,3 trên 100.000 đối với nam và 63,5 trên 100.000 đối với nữ [3]. Nghiên cứu khác trên quân đội Hoa Kỳ từ năm 2000 đến 2009 báo cáo tỷ lệ mắc hội chứng cổ-vai-cánh tay là 1,79 trên 1.000 người mỗi năm [4].

Theo $Y$ học cổ truyền (YHCT), hôi chứng cổvai-cánh tay được xếp vào phạm vi Chứng tý đã được mô tả rất rõ ràng trong các y văn cổ. Nguyên nhân do phong, hàn, thấp tà xâm nhập vào cơ thể nhân khi chính khí hư suy, làm khí huyết vận hành trong kinh lạc bị trở trệ không thông mà sinh bệnh.

Cảnh tam chẩm là trường phái châm cứu của Giáo sư Cân Thụy (靳瑞) - Đại học Trung y dược Quảng Châu sáng lập [5]. Đây là phương pháp châm cứu chọn 3 huyệt dựa trên nguyên tắc phối hợp giữa huyệt tại chỗ với huyệt theo kinh, mối liên hệ giữa tạng phủ với kinh lạc, khí huyết [6]. Phương pháp này đã được tổ hợp thành 42 loại và đã ứng dụng thành công trên lâm sàng (tị, nhãn, nhĩ, thiệt, trí, não, nhiếp, nhiếp thượng, xoa, đột, cảnh (cổ), bối, kiên, thủ, túc, yêu, tất, hòa, ủy, hạt, nhũ, vị, trường, đởm, niệu, chi, phì, nhàn, âm, dương, bế, thoát tam châm, tứ thần châm, định thần châm, vựng thống châm, diện cơ châm, diện than châm, thủ trí châm, tọa cốt châm, túc trí châm, khởi bế châm, lão ngai châm). Xuất phát từ thực tiễn lâm sàng đó, cùng với mong muốn góp phần nâng cao hiệu quả điều trị, chúng tôi tiến hành nghiên cứu với muc tiêu sau:

Theo dõi tác dụng không mong muốn của bài thuốc "TK1-HV" kết hợp cảnh tam châm trong quá trình điều trị.

\section{II. ĐỐI TƯỢNG VÀ PHƯƠNG PHÁP NGHIÊN CỨU 2.1. Địa điểm, thời gian, đối tượng nghiên cứu}


- Địa điểm nghiên cứu: Bệnh viện Y học cổ truyền Bộ công an.

- Đối tượng nghiên cứu: Bệnh nhân trên 18 tuổi được xác định mắc hội chứng cổ-vai-cánh tay.

- Thời gian nghiên cứu: Nghiên cứu được thực hiện từ 10/2018 - 8/2019

\subsection{Phương pháp nghiên cứu}

\subsubsection{Thiết kế nghiên cứu}

Nghiên cứu được tiến hành theo phương pháp can thiệp lâm sàng, so sánh trước và sau điêu trị, có nhóm chứng. mấu

2.2.2. Cỡ mấu và phương pháp chọn - Cõ mẫu:

$\mathrm{n}=\frac{Z_{\left(1-{ }_{2}{ }_{2} \times{ } \times \overline{(1-\mu)}\right.}+Z_{\beta} \times \overline{\mu_{1} \times 1-\mu_{1}+\mu_{2} \times\left(1-\mu_{2}\right)}}{\left(\mu_{1}-\mu_{2}\right)^{2}}$

[7],[8]. Thay vào công thức ta được cõ mẫu là 23 bệnh nhân.

2.3. Các kỹ thuật sử dụng trong nghiên cứu

- Công cụ điện châm và kỹ thuật điện châm:
Máy điện châm M8, kim châm cứu dùng 1 lần, bông, cồn 70 độ, pank có mấu, khay quả đậu.

- Công cụ và kỹ thuật đánh giá mức độ đau theo thang điểm VAS: Mức độ đau của bệnh nhân được đánh giá theo thang điểm VAS từ 1 đến 10 bẳng thước đo độ của hãng Astra- Zeneca

- Công cụ và kỹ thuật đo tầm vận động cột sống cổ:Thước đo tâm vận động cột sống.

- Công cụ đánh giá mức độ hạn chế sinh hoạt hàng ngày

2.4. Chất liệu nghiên cứu

- Bài thuốc TK1-HV

- Phác đồ huyệt Cảnh tam châm

- Phác đồ huyệt điện châm

2.5. Phương pháp xử lý số liệu. Số liệu sau thu thập được xử lý bằng thuật toán thống kê y sinh học dưới sự hố trợ của phần mềm SPSS 20.0 của IBM. Thuật toán được sử dụng bao gồm: đếm số lượng, tính tỷ lệ \%, kiểm định Ttest, khi bình phương. Với mức ý nghĩa $95 \%$, kết quả có ý nghĩa thống kê với $p<0,05$.

\section{KẾT QUẢ NGHIÊN CỨU}

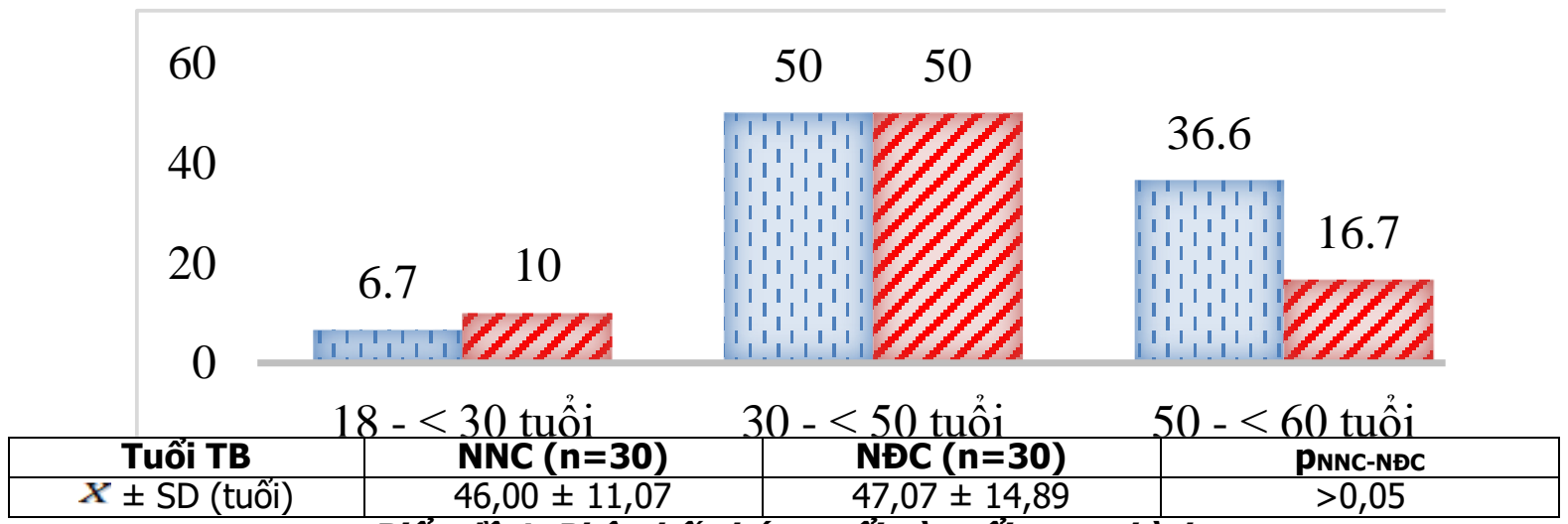

\section{Biếu đồ 1. Phân bố nhóm tuối và tuối trung binh}

Hầu hết bệnh nhân đều ở nhóm tuổi từ $30-<50$ tuổi (tỷ lệ bằng nhau và bằng $50 \%$ ở cả NNC và NĐC); thấp nhất ở nhóm từ $18-<30$ tuổi. Tuổi TB là 46,00 \pm 11,07 (tuổi) ở NNC và 47,07 \pm 14,89 (tuôii) $(p>0,05)$

Bảng 1. Tác dụng không mong muốn của bài thuốc TK1-HV

\begin{tabular}{|c|l|}
\hline Biếu hiệ̂n & Ngày xuất hiện \\
\hline Buồn nồn & Không xuất hiệ̂n \\
\hline Nôn & Không xuất hiện \\
\hline Đau bụng & Không xuất hiện \\
\hline Đi ngoài phân lỏng & Không xuất hiệ̂n \\
\hline Sấn ngứa/di ứng & Không xuất hiện \\
\hline Đau đâuu & Không xuất hiệ̂n \\
\hline Hoa mắt chóng mặt & Không xuất hiện \\
\hline
\end{tabular}

Nhận xét: Trong quá trình 28 ngày dùng bài thuốc TK1-HV liên tục, nghiên cứu không ghi nhận được tác dụng không mong muốn.
Bảng 3.2. Tác dụng không mong muốn của phương pháp cảnh tam châm trong quá trinh điều trị

\begin{tabular}{|c|c|}
\hline Biểu hiện & Ngày xuất hiện \\
\hline Chảy máu & Không xuất hiệ̂n \\
\hline Đau sưng & Không xuất hiệ̂n \\
\hline Sấn ngứa & Không xuất hiệ̣n \\
\hline Abces & Không xuất hiện \\
\hline Vựng châm & Không xuất hiệ̂n \\
\hline Không ghi nhân đươc các biếu hiện bất
\end{tabular}
thường tại vị trí thực hiện thủ thuật cảnh tam châm. Không có bệnh nhân nào xuất hiện vựng châm trong quá trình 28 ngày điều trị. 
Bảng 3. Sư thay đổi dấu hiêuu sinh tồn trước và sau điều trị

\begin{tabular}{|c|c|c|c|c|}
\hline \multicolumn{2}{|c|}{ Chỉ số } & $D_{0}(X \pm S D)$ & $D_{28}(X \pm S D)$ & PDO-D28 \\
\hline \multirow{3}{*}{ Mạch (lần/phút) } & NNC $(n=30)$ & $77,89 \pm 5,66$ & $77,34 \pm 4,01$ & $>0,05$ \\
\hline & $\operatorname{NĐC}(n=30)$ & $78,00 \pm 4,67$ & $78,21 \pm 4,00$ & $>0,05$ \\
\hline & PNNC-NAC & $>0,05$ & $>0,05$ & \\
\hline \multirow{3}{*}{$\begin{array}{c}\text { Huyết áp TB (mmHg) } \\
\pm S D\end{array}$} & $\operatorname{NNC}(n=30)$ & $90,01 \pm 5,75$ & $90,23 \pm 6,09$ & $>0,05$ \\
\hline & $\operatorname{NĐC}(n=30)$ & $90,00 \pm 7,34$ & $89,91 \pm 5,44$ & $>0,05$ \\
\hline & DNNC-NEC & $>0,05$ & $>0,05$ & \\
\hline
\end{tabular}

Nhận xét: Không có sự thay đối có ý nghĩa thống kê trên chỉ số mạch và huyết áp trung bình của bệnh nhân NNC và NĐC (p>0,05).

Bảng 4. Sự thay đôi chí số công thức máu trước và sau điều trị

\begin{tabular}{|c|c|c|c|c|}
\hline \multicolumn{2}{|c|}{ Chỉ số } & $D_{0}$ & $D_{28}$ & PDO-D28 \\
\hline \multirow{3}{*}{ Hồng cầu $(T / I)$} & NNC $(n=30)$ & $3,89 \pm 0,41$ & $3,93 \pm 0,59$ & $>0,05$ \\
\hline & $\operatorname{NDC}(n=30)$ & $4,00 \pm 0,13$ & $4,01 \pm 0,67$ & $>0,05$ \\
\hline & PNNC-NEC & $>0,05$ & $>0,05$ & \\
\hline \multirow{3}{*}{ Bạch câu (G/l) } & NNC $(n=30)$ & $7,33 \pm 1,64$ & $7,68 \pm 1,42$ & $>0,05$ \\
\hline & $\operatorname{NDC}(n=30)$ & $7,09 \pm 1,82$ & $7,56 \pm 1,13$ & $>0,05$ \\
\hline & PNNC-NEC & $>0,05$ & $>0,05$ & \\
\hline \multirow{3}{*}{ Tiểu câu (G/I) } & $\operatorname{NNC}(n=30)$ & $214,56 \pm 32,56$ & $210,89 \pm 28,77$ & $>0,05$ \\
\hline & $\operatorname{NDC}(n=30)$ & $210,09 \pm 45,89$ & $214,77 \pm 65,04$ & $>0,05$ \\
\hline & PNNC-NEC & $>0,05$ & $>0,05$ & \\
\hline
\end{tabular}

Nhận xét: Các chỉ số hồng cầu, bạch cầu, tiếu cầu của NNC và NĐC đều thay đối không có ý nghĩa thống kê sau 28 ngày điều tri.

Bảng 5. Sự thay đổi chỉ số sinh hóa máu trước và sau điều trị

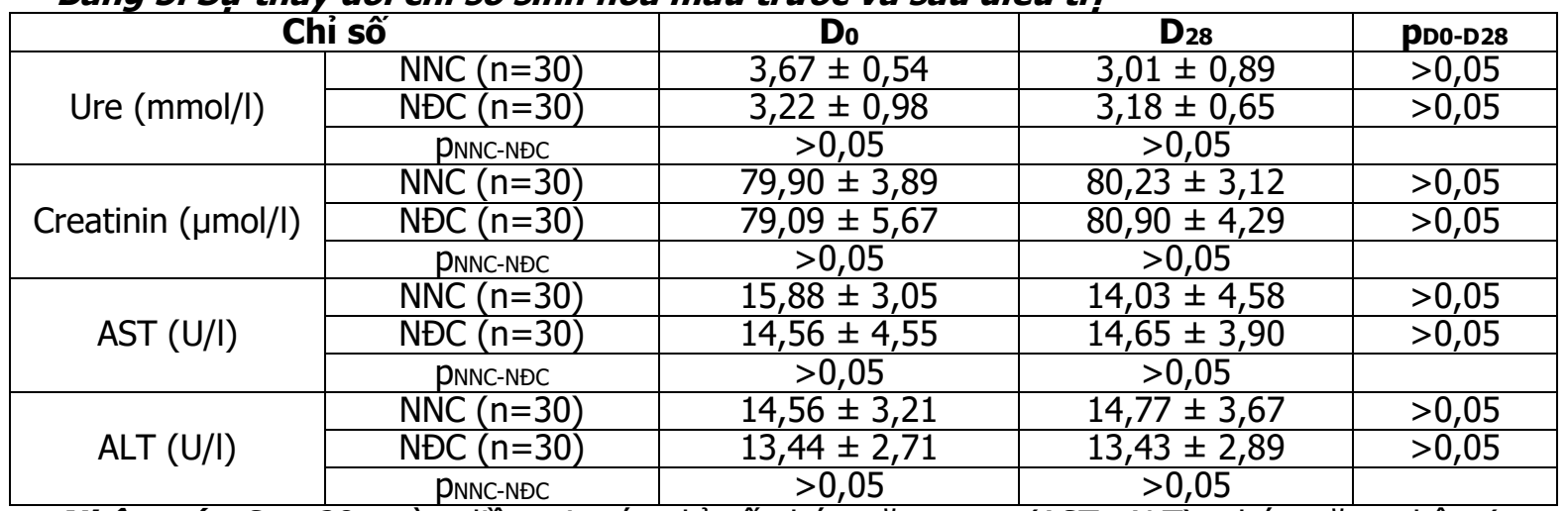

Nhận xét: Sau 28 ngày điêu trị, các chỉ số chức năng gan (AST, ALT), chức năng thận (ure, creatinine) của bệnh nhân đều nằm trong giới hạn bình thường. Sự thay đổi không có ý nghĩa thống kê $(p>0,05)$.

\section{BÀN LUẦN}

Về tuổi và nhóm tuổi, bên canh yếu tố dịch tễ học của bệnh lý, do địa bàn nghiên cứu là Bệnh viện YHCT Bộ công an, nơi hàng năm tiếp nhận một lượng lớn bệnh nhân là cán bộ ngành và nhân dân địa phương, do đó, tuổi TB của bệnh nhân trong nghiên cứu khá cao (46-47 tuổi ở cả NNC và NĐC - biểu đồ 3.1) với phân bố ở nhóm 30 - 50 tuổi chiếm $50 \%$ đối tượng mắc hội chứng cổ-vai-cánh tay. Điều này một phần được lý giải bởi những những biến đổi về hình thái các đốt sống cổ - nguyên nhân gây thoái hóa dẫn đến hội chứng cổ-vai-cánh tay gây ra các triệu chứng lâm sàng, cận lâm sàng điển hình thường xuất hiện khi bệnh nhân bước vào tuổi trung niên, một phần là bởi đặc thù địa lý của đơn vị tiến hành nghiên cứu - điều này đồng thời cũng làm ảnh hưởng đến chất lượng cuộc sống và hiệu quả lao động, khiến bệnh nhân phải nhập viện điều trị. Kết quả nghiên cứu của chúng tôi khá tương đồng với Trịnh Thị Hương Giang [9],

Không bệnh nhân nào có biểu hiện sẩn ngứa, sưng tấy, nóng đỏ, chảy máu tại vị trí thực hiện thủ thuật cảnh tam châm. Điều này được đảm bảo do 2 lý do: Thứ nhất, nghiên cứu viên luôn đảm bảo vô khuẩn trong quá trình thực hiện thủ thuật (buồng bệnh, găng tay, kim thực hiện cảnh tam châm); thứ hai, nghiên cứu viên đã được đào 
tạo và có kinh nghiệm trong thực hiện thủ thuật cành tam châm trên nhiêu bệnh nhân khác nhau.

Trong quá trình 28 ngày uống TK1-HV dưới dạng nước sắc, chúng tôi không ghi nhân đươoc các tác dụng không mong muốn của bài thuốc TK1-HV. Các bệnh nhân đều ăn uống, ngủ nghỉ bình thường, không có hiện tượng đau bụng đi ngoài, buồn nôn, nôn, sẩn ngứa, dị ứng...

Dấu hiệu sinh tồn (mạch, huyết áp trung bình) được chúng tôi đánh giá tại 2 thời điểm là thời điểm trước điêuu trị (ngày $D 0$ ) và thời điểm D28 khi kết thúc liệu trình can thiệp. Các số liệu định lượng thu thập được cho thây không có sự khác biệt về các chỉ số này. Mạch và huyết áp trung bình của cả 2 nhóm bệnh nhân đều nằm trong giới hạn bình thường.

Kết quả sau 28 ngày dùng TK1-HV kết hợp cảnh tam châm hoăc TK1-HV kết hợp điên châm cho thấy các chỉ số công thức máu cơ bản (hông câu, bạch câuu, tiểu câu) đều nằm trong giới hạn bình thường. Không có sự khác biệt đáng kể nào được ghi nhận trong quá trình diễn ra nghiên cứu này. Chỉ số chức năng gan thận của bệnh nhân NNC và NĐC đều nằm trong giới hạn bình thường trước và sau khi kết thúc liệu trình điêuu trị.

Kết quả nghiên cứu này cho thấy, bài thuốc TK1-HV kết hợp cảnh tam châm điều trị hội chứng cổ-vai-cánh tay do thoái hóa cột sônng cổ an toàn trên lâm sàng.

\section{KẾT LUÂN}

Không ghi nhận các tác dụng không mong muốn trên lâm sàng, dấu hiệu sinh tồn; không thấy sự thay đổi chỉ số huyết học và sinh hóa cơ bản sau 28 ngày sử dụng.

\section{VI.KHUYẾN NGH!}

- Nghiên cứu phương pháp cảnh tam châm trên số lượng bệnh nhân lớn hơn, tại một số cơ sở điêu trị khác.

- Đánh giá tác dụng độc lập của phương pháp cảnh tam châm trên lâm sàng.

\section{TÀI LIỆ THAM KHẢO}

1. Bộ Y tế (2016). Hướng dẫn chẩn đoán và điều tri các bệnh cơ xương khớp, Nhà xuất bản Y học, Hà Nội, 145-153.

2. Caridi J.M., Pumberger M., Hughes A.P. (2011). Cervical radiculopathy: a review, HSS J Musculoskelet J Hosp Spec Surg, 7(3), pg 265-272.

3. Radhakrishnan K., Litchy W.J., O'Fallon W.M. et al (1994). Epidemiology of cervical radiculopathy. A population-based study from rochester, minnesota, 1976 through 1990, Brain, 117, pg 325-335.

4. Schoenfeld A.J, George A.A., Bader J.O. et al (2012). Incidence and epidemiology of cervical radiculopathy in the united states military: 2000 to 2009, J Spinal Disord Tech, 25, pg 17-22.

5. 75. Liao $W$. ., Tang $C$. , Zhang J. (2018). Discussion on the principle and treatment pathway of Jin's three-needle technique for mind regulation and treatment from the "Adjusting qi to regulate mind, adjusting blood to regulate mind", Zhongguo Zhen Jiu, 38(11), pg 1235-1238.

6. Yuan Qing, Luo Guangming, Jeffrey Winsauer et al (2004). Chinese-English explanation of Jin' 3-needle technique, Shanghai Scientific and technologicl Literature publishing house ${ }_{h}$ China.

7. Nguyến Văn Tuấn (2008). $Y$ học thực chứng, Nhà xuất bản $Y$ hoc, Hà Nôi, 90 .

8. Lưu Ngọc Hoạt (2018). Phương pháp viết đề cương nghiên cứu khoa học, Nhà xuất bản Y học, Hà Nô̂i.

9. Trịnh Thị Hương Giang (2019). Đánh giá hiêuu quả điều tri hội chứng cố vai canh tay do thoái hóa cột sống cổ bằng điện châm, xoa bóp bấm huyệt kết hợp thủy chẩm Nucleo C.M.P, Luận văn Thạc sỹ Y học, Trường Đại học Y Hà Nội.

\section{NGHIÊN CỨU ĐĂC ĐIỂM XUẤT HUYẾT DƯỚI NHÊ̂N TRONG GIÁM ĐİNH Y PHÁP}

\section{TÓM TẮT}

Xuất huyết dưới nhện (XHDN) là tình trang chảy máu vào một vùng không gian quanh nhu mồ não gọi là khoang dưới nhện, khoang này nằm giữa 2 lớp

1 Trường Đại học Y Hà Nội

2Viên Pháp y quốc gia

Chịu trách nhiệm chính: Nguyễn Tuấn Anh

Email: tuananhyhn@gmail.com

Ngày nhân bài: 25.11.2020

Ngày phản biên khoa hoc: 29.12.2020

Ngày duyệt bài: 7.01.2021

\section{Nguyễn Tuấn Anh", Đào Hoàng Diễm², Lưu Sỹ Hùng1}

màng não là màng nhện ở ngoài và màng mềm ở trong, có thể chia làm 2 loai là XHDN chấn thương và XHDN không chấn thương ${ }^{[1]}$. Nghiên cứu được thực hiện tại Bộ môn Y Pháp và khoa Giải Phẫu Bệnh Pháp Ý bệnh viện Hữu Nghị Việt Đức từ 01/2004 đến 12/2017 trên 49 nạn nhân tử vong do XHDN. Nạn nhân nhỏ tuổi nhất là 15 tuổi và lớn tuổi nhất là 85 tuổi. Tuổi trung bình là 33.5 tuổi, gặp nhiêu nhất là 25 tuổi, đa số là nam giới $(97.96 \%)$, hoàn cảnh xảy ra chủ yếu do bị đánh 79.6\%. XHDN liên quan đến tổn thương da và tổ chức dưới da chiếm 95,9\%, võ xương sọ $75,5 \%$, phù não $77.6 \%$, tỷ lệ XHDN do chấn thương chiếm $89,8 \%$. 